\title{
CARACTERIZAÇÃo E AVALIAÇÃO SENSORIAL DE BARRA DE CEREAIS FUNCIONAL DE ALTO TEOR PROTÉICO E VITAMÍNICO ${ }^{1}$
}

\author{
Daniela G.C. FREITAS ${ }^{2, *}$, Roberto H. MORETTI ${ }^{2}$
}

\begin{abstract}
RESUMO
Barras de cereais foram introduzidas no mercado há cerca de uma década como alternativa "saudável" de confeito. Concomitantemente, alimentos como a soja, ricos em vitaminas e minerais e com propriedades antioxidantes vêm recebendo grande aplicação em produtos de alegação funcional, pois previnem contra doenças cardiovasculares e crônico-degenerativas. Considerando o crescimento do segmento de barra de cereais no setor de alimentos, desenvolveu-se uma formulação de barra de cereais de alto teor protéico e vitamínico, à base de proteína de soja texturizada, gérmen de trigo e aveia, enriquecida de ácido ascórbico e acetato de $\alpha$-tocoferol. As matérias-primas e a formulação final da barra de cereais foram submetidas a análises para caracterização e três formulações, variando o teor de ácido ascórbico, foram avaliadas quanto à preferência sensorial e intensidade ideal de doçura e acidez. A proteína de soja texturizada utilizada apresentou elevados teores dos oligossacarídeos rafinose e estaquiose ( $1,92 \mathrm{~g} / 100 \mathrm{~g} \mathrm{e}$ $4,66 \mathrm{~g} / 100 \mathrm{~g})$ e de isoflavonas totais $(283,49 \mathrm{mg} / 100 \mathrm{~g})$ se comparados ao grão, farinha integral e isolado protéico. A formulação final da barra de cereais apresentou $15,31 \%$ de proteína e elevado teor de vitamina E (118,0 mg/100 g) e minerais como fósforo, ferro e manganês. A formulação adicionada de $1,1 \mathrm{~g} / 100 \mathrm{~g}$ de ácido ascórbico obteve maior preferência sensorial diferindo das demais amostras $(\mathrm{p} \leq 0,05)$.

Palavras-chave: barra de cereais, proteína de soja, gérmen de trigo, preferência sensorial.
\end{abstract}

\section{SUMMARY}

CHARACTERIZATION AND SENSORIAL EVALUATION OF FUNCTIONAL CEREAL BAR. Cereal bars were introduced over a decade ago as a "healthy" alternative confectionery. Concomitantly, foods as soybean, with high vitamin and mineral levels and antioxidants properties come receiving great application in functional products, because they can prevent against chronic-degenerative illnesses of the heart. Considering the growth of the segment of cereal bars in the food sector, it was developed a formulation with high protein and vitamin levels cereal bar based on textured soy protein, wheat germ and oat, enriched with acid ascorbic and acetate of $\alpha$-tocoferol. The cereal bar and its ingredients had been submitted to the analyses for characterization and three formulations, varying the content of acid ascorbic; they had also been evaluated as a sensorial preference and an ideal intensity of sweetness and acidity. The textured soy protein used presented high levels of oligosaccharides raffinose and stachiose ( $1.92 \mathrm{~g} / 100 \mathrm{~g} \mathrm{e} 4.66 \mathrm{~g} / 100 \mathrm{~g}$ ) and of total isoflavones $(283.49 \mathrm{mg} / 100 \mathrm{~g})$, when compared with the grain, integral flour and isolated protein. The final formulation of the cereal bar presented $15.31 \%$ of protein, high vitamin E content (118.0 $\mathrm{mg} / 100 \mathrm{~g}$ ) and minerals such as phosphorus, iron and manganese. The $1.1 \mathrm{~g} / 100 \mathrm{~g}$ added formulation of acid ascorbic got greater significantly sensorial preference, differing from the other samples $(\mathrm{p} \leq 0.05)$.

Keywords: cereal bar, soy protein, wheat germ, sensorial preference.

\section{1 - INTRODUÇÃO}

Barras de cereais foram introduzidas há cerca de uma década como uma alternativa "saudável" de confeito, quando consumidores se mostravam mais interessados em saúde e dietas [5]. Alternativa saudável às barras de chocolate, o produto foi direcionado no Brasil inicialmente aos adeptos de esportes radicais e, com o tempo, conquistou até executivos de banco.

Empresas nacionais disputam um mercado de R\$ 80 milhões [3]. Atualmente, enquanto no Brasil consomem-se US\$ 4 milhões de barras de cereais por ano, os Estados Unidos dão conta de US\$ 2,9 bilhões, sendo que o consu-

\footnotetext{
${ }^{1}$ Recebido para publicação em 26/1/2005. Aceito para publicação em 28/4/2006 (001473)

${ }^{2}$ Faculdade de Engenharia de Alimentos, Departamento de Tecnologia de Alimentos da Universidade Estadual de Campinas, Cidade Universitária "Zeferino Vaz"

Rua Monteiro Lobato, $s / n^{\circ}$, Campinas (SP)

CEP 13083-862 - Caixa Postal 6121

E-mail:danieladegrandi@yahoo.com.br

*A quem a correspondência deve ser enviada
}

mo americano cresceu cerca de $40 \%$ nos últimos dois anos [13].

Segundo PALAZZOLO [23], o catalisador para o crescimento no segmento de barra de cereais nos Estados Unidos, a partir da última década, foram produtos inovadores e um foco em conveniência e saúde. PEHANICH [24] reportou que barras nutricionais e energéticas vêm ganhando o mercado consumidor nos segmentos diet, "para mulheres", "atletas de fim de semana”, "esportistas", e outros.

A associação entre barra de cereais e alimentos saudáveis é uma tendência já documentada no setor de alimentos, o que beneficia o mercado destes produtos [4]. Esta crescente preocupação por uma alimentação saudável que, além de alimentar promova a saúde, coloca alguns alimentos e ingredientes na lista de preferência de um número cada vez maior de consumidores brasileiros, como a soja, lecitina de soja, gérmen de trigo e antioxidantes.

A soja é rica em proteínas, possui isoflavonas e outras substâncias capazes de atuar na prevenção de doenças crônico-degenerativas. Epidemiologistas focalizaram sua atenção na soja e seus derivados porque as taxas de problemas cardiovasculares, sintomas decorrentes da menopausa, 
câncer no seio e de próstata e osteoporose, entre outras doenças, eram muito menores em países orientais do que as taxas de países ocidentais, com baixo consumo de fitoestrógenos (isoflavonas) da soja. Sua atividade é semelhante aos hormônios femininos, dentre os quais a genisteína e a daidzeína, que são considerados vitais para a saúde da mulher. Quando ingeridos, os fitoestrógenos da soja sofrem transformação estrutural no decorrer da digestão e são convertidos numa forma fraca de estrógeno.

As isoflavonas têm capacidade de normalizar os níveis de estrógenos circulantes, quer estejam altos ou baixos. Acredita-se que a menor incidência de sintomas da menopausa, osteoporose e cânceres estrógeno-dependentes nessa população esteja relacionada à ingestão de isoflavonas, contidas principalmente na soja [39, 16, 7, 20]. As isoflavonas podem também agir na redução da incidência de doenças do coração e nas disfunções das taxas colesterolêmicas [28].

As experiências pessoais de um grande número de químicos, médicos e outros, assim como RINSE [27], sugerem que a aterosclerose é uma doença de deficiência, que pode ser combatida eficientemente com o uso de suplementos alimentares. Um fator importante para o favorecimento da aterosclerose é a oxidação das lipoproteínas do sangue. Lipídios poliinsaturados oxidam-se facilmente, especialmente no meio do sangue arterial, rico em oxigênio. A hipótese entre oxidação e aterosclerose implica que antioxidantes são capazes de inibir a oxidação de lipoproteínas na parede arterial e então retardar a aterogênese.

Muitos estudos em animais vêm usando altas doses de antioxidantes, mostrando ser efetivos agentes antiateroscleróticos quando dados em doses farmacológicas [11, 36, 18, 17]. Vitaminas E e C são consideradas os mais importantes nutrientes antioxidantes, e sua deficiência está associada ao aumento de riscos de doenças coronárias [29].

A vitamina $\mathrm{E}$ (tocoferol) é o principal antioxidante lipossolúvel nas membranas celulares. Protege contra a oxidação lipídica por atuar diretamente sobre radicais livres derivados do oxigênio. A vitamina $\mathrm{C}$ interage com o tocoferol, regenerando o tocoferol reduzido, e desta forma, a relação vitamina C:vitamina $\mathrm{E}$ pode ser biologicamente mais importante do que os níveis absolutos de vitamina $\mathrm{C}[34,8]$.

Os subprodutos das fábricas de farinha de trigo, os quais incluem várias formas de fibras (ou farelo), o gérmen e os resíduos da etapa de "limpeza" (cleaning house ou screen room), representam cerca de $25 \%$ do grão e são considerados economicamente significantes. Tradicionalmente, as camadas externas do grão têm sido destinadas para a alimentação animal, pelo elevado teor de fibras de sabor amargo e pela susceptibilidade a rancidez. No entanto, representam um total de $20 \%$ do trigo, dos quais 16 a 17\% são proteínas [38]. O valor nutritivo das proteínas do farelo é superior ao da proteína do endosperma. As gorduras são altamente insaturadas, e o teor de minerais e vitaminas é elevado [25].
Assim, visando o aproveitamento de ingredientes cada vez mais usados em alimentos com alegação funcional e o aumento no consumo de barras de cereais, principalmente por ser um alimento saudável e prático, este trabalho teve como objetivos a elaboração e caracterização de uma formulação de barra de cereais sabor banana, a base de proteína de soja texturizada, gérmen de trigo e aveia, suplementada com vitaminas C e E, e a avaliação sensorial do produto quanto à sua preferência pelos consumidores.

\section{2 - MATERIAL E MÉTODOS}

\section{1 - Material}

Foram utilizados os seguintes ingredientes para a formulação da barra de cereais: proteína texturizada de soja Maxten R-120 (Bunge Alimentos S/A, Esteio - Brasil); gérmen de trigo e aveia laminada integral (Natu's Alimentos Naturais, Hortolândia - Brasil); lecitina de soja Lecsam L (Bunge Alimentos S/A, Esteio - Brasil); banana desidratada (Naturama Produtos Naturais Ltda., Campinas - Brasil); ácido ascórbico e vitamina E 50\% tipo CWS/F (Roche Vitaminas Brasil Ltda., São Paulo - Brasil); xarope de glicose de milho Excell 1040 e Malto-dextrina Mor Rex 1910 (Corn Prodcts Brasil, Balsa Nova - Brasil); gordura vegetal hidrogenada Primor (Bunge Alimentos S/A, São Paulo - Brasil).

Após uma seqüência de testes, obteve-se a formulação final da barra de cereais, apresentada na Tabela 1.

TABELA 1 - Formulação final de barra de cereais funcional sabor banana

\begin{tabular}{|c|c|c|c|}
\hline \multirow{2}{*}{ Ingrediente } & \multicolumn{3}{|c|}{ Formulação $(\mathrm{g} / 100 \mathrm{~g})$} \\
\hline & A & B & C \\
\hline \multicolumn{4}{|l|}{ Xarope de aglutinação } \\
\hline Açúcar integral* & 25,5 & 25,5 & 25,5 \\
\hline Xarope de glicose & 12,5 & 12,5 & 12,5 \\
\hline Malto-dextrina & 6,5 & 6,5 & 6,5 \\
\hline Glicerina & 1,5 & 1,5 & 1,5 \\
\hline Gordura vegetal & 1,5 & 1,5 & 1,5 \\
\hline Água & 2,5 & 2,5 & 2,5 \\
\hline \multicolumn{4}{|l|}{ Ingredientes secos } \\
\hline Proteína texturizada de soja & 15,4 & 15,4 & 15,4 \\
\hline Gérmen de trigo torrado** & 10,5 & 10,5 & 10,5 \\
\hline Aveia laminada integral & 10,5 & 10,5 & 10,5 \\
\hline Lecitina de soja & 4,5 & 4,5 & 4,5 \\
\hline Banana desidratada & 6,8 & 7,7 & 8,6 \\
\hline Vitamina C (ácido ascórbico) & 2,0 & 1,1 & 0,2 \\
\hline Vitamina $\mathrm{E}$ (acetato de $\alpha$-tocoferol $50 \%$ ) & 0,3 & 0,3 & 0,3 \\
\hline
\end{tabular}

\section{2 - Métodos}

\subsection{1 - Processamento}

A preparação do xarope de aglutinação se deu em recipiente de aço inoxidável, onde os ingredientes foram 
aquecidos sob agitação, com acompanhamento do teor de sólidos solúveis totais em refratômetro digital Leica AR200 (Leica Microsystems Inc., EUA), até a obtenção de um xarope de $85-89^{\circ}$ Brix. Os ingredientes secos foram misturados ao xarope de aglutinação à temperatura em torno de $95^{\circ} \mathrm{C}$, seguida de enformagem e prensagem, para a obtenção de formato. Após resfriamento, as barras de cereais foram desenformadas e cortadas em tamanhos retangulares, de peso constante de 25 g cada unidade. As barras de cereais foram então acondicionadas individualmente em embalagens de filme flexível (PET/PEBD/AL/PEBD) ${ }^{1^{*}}$.

\subsection{2 - Caracterização da matéria-prima e da barra de cereais funcional}

Composição centesimal aproximada - as principais matérias-primas utilizadas (proteína de soja texturizada, aveia integral e gérmen de trigo) e a barra de cereais foram submetidas a análises físico-químicas para determinação de proteínas, método de Kjeldael descrito pela AOAC [1]; determinação de matéria graxa, método de Soxhlet descrito pela AOAC [ 1]; determinação de umidade, método descrito pelas NORMAS ANALÍTICAS DO INSTITUTO ADOLFO LUTZ [22]; determinação de cinzas, método descrito pela AOAC [1]; determinação de fibras através de método enzimático [33] e atividade de água em equipamento AQUA Lab CX 2 (Degagon Devices Inc., Washington - EUA) Foram realizadas as análises de macro e micro minerais da barra de cereais, segundo SARRUGE \& HAAG [30].

Oligossacarídeos em proteína texturizada de soja - os açúcares sacarose, rafinose e estaquiose foram extraídos e determinados por HPLC segundo VIDAL-VALVERDE, FRIAS \& VALVERDE [37]. Foi utilizada coluna Shim-Pack CLCNH2 (250 mm) e detector de índice de refração. Acetonitrila: água (75:25) foi utilizada como fase móvel num fluxo de $1,0 \mathrm{~mL} / \mathrm{min}$. Todas as soluções foram filtradas em filtro millex $0,45 \mu \mathrm{m}$. Foram utilizados padrões sacarose, rafinose e estaquiose (Sigma Chemical Co., St. Louis-Missouri).

Isoflavonas em proteína texturizada de soja - foram extraídas a partir de $100 \mathrm{mg}$ de amostra de proteína moída, colocados em tubos de ensaio com 4,0 mL de etanol $70 \%$ contendo $0,1 \%$ de ácido acético e deixados à temperatura ambiente por $5 \mathrm{~h}$, com agitação a cada 15 minutos. Após centrifugação de 1,5 mL da mistura por $10 \mathrm{~min}$ a $13.346 \mathrm{~g} \mathrm{a} 10^{\circ} \mathrm{C}$, o sobrenadante foi analisado por HPLC. Foi utilizada coluna de fase reversa YMC-Pack ODS-C-18 (4,6×250 mm) e o efluente foi monitorado por detector UV a $260 \mathrm{~nm}$. A fase móvel foi acetonitrila com $0,1 \%$ de ácido acético (A) e água com $0,1 \%$ de ácido acético (B). As condições iniciais foram $20 \%$ do solvente $\mathrm{B}$, em gradiente linear, passando para 50\% depois de 20 min. Todas as soluções foram filtradas em filtro millex 0,45 $\mu \mathrm{m}$. Foram utilizados padrões daidzeína, genisteína, daidzina e genistina (Sigma Chemical Co., St. Louis-Missouri).

"Composição do filme: poliéster (PET)/polietileno (PEBD)/alumínio (AL)/ polietileno (PEBD); fornecido por Shellmar Embalagens Modernas Ltda., São Paulo/SP, Brasil
Determinação de tocoferóis totais (Vitamina E) - os tocoferóis totais foram determinados em amostras de gérmen de trigo, gérmen de trigo torrado e lecitina de soja, segundo CONTRERAS GUZMÁN \& STRONG [10]. O conteúdo de vitamina $\mathrm{E}$ na barra de cereais foi extraído a partir de 2,5 g de amostra de barra de cereais previamente congelada e reduzida em moinho em $25,0 \mathrm{~mL}$ de dimetilsulfóxido (DMSO) em agitação magnética por 20 min. Foi adicionado 50,0 mL de hexano seguido de agitação por $15 \mathrm{~min}$. A fase superior foi transferida e evaporada, dissolvida em 10,0 mL de metanol, filtrada em filtro millex de 45,0 $\mu \mathrm{m}$ e 20,0 $\mu \mathrm{L}$ injetado no HPLC, segundo LEENHEER; LAMBERT \& RUYTER [19]. Foi utilizada Coluna ODS 2 (150x4,6 mm) e detector UV a $280 \mathrm{~nm}$. A fase móvel foi metanol HPLC $100 \%$ a $2,0 \mathrm{~mL} / \mathrm{min}$. Foi utilizado padrão vitamina E 50\% tipo CWS/F (Roche Vitaminas Brasil Ltda., São Paulo -Brasil).

\subsection{3 - Avaliação sensorial}

Amostras de um terço de barra de cereais foram apresentadas aos consumidores à temperatura ambiente, com códigos de três dígitos. A ordem de apresentação foi balanceada randomicamente pelo delineamento de uma tabela de números. A avaliação sensorial foi realizada por uma equipe de 45 consumidores, estudantes da Universidade Estadual de Campinas familiarizados com testes sensoriais, de ambos os sexos e idades entre 20 e 40 anos, representativos do público consumidor.

O procedimento se deu em uma sala de avaliação sensorial com cabines individuais, sob luz branca equivalente a luz do dia. A sessão foi conduzida apresentando-se três amostras de barra de cereais correspondentes às três diferentes formulações que variaram o teor de ácido ascórbico em 2,0 g/100 g (amostra A); 1,1 g/100 g (amostra B); e $0,2 \mathrm{~g} / 100 \mathrm{~g}$ (amostra C), apresentadas monadicamente. Escalas hedônicas não estruturadas de nove pontos que abrangiam desgostei muitíssimo a gostei muitíssimo foram utilizadas no teste de preferência das barras de cereais. A intensidade de ideal de doçura e ideal de acidez foi avaliada pela escala estruturada (-4: extremamente menos doce/ácido que o ideal; +4: extremamente mais doce/ácido que o ideal), conforme STONE \& SIDEL [35].

\subsection{4 - Análise dos dados}

Os dados obtidos foram avaliados pelo método de análise de variância (ANOVA) com comparação de médias pelo teste de Tukey, por meio do programa estatístico SAS [31].

\section{3 - RESULTADOS E DISCUSSÃO}

\section{1 - Caracterização da matéria-prima e da barra de cereais funcional}

A formulação final da barra de cereais funcional apre-

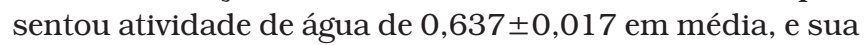
composição centesimal, bem como das principais matérias- 
primas utilizadas estão descritas na Tabela 2. Verifica-se que os valores encontrados para a composição centesimal aproximada do gérmen de trigo são semelhantes aos dados encontrados por MARQUES [21]; SIDHU, AL-HOOT \& ALSAQER [32]; e POMERANZ [26].

O gérmen apresentou conteúdo de proteínas superior ao relatado pelos dois últimos autores, que variou em torno de 25 a $28 \%$. A composição centesimal da aveia apresentou-se em concordância com a encontrada por HART [15]. O conteúdo de proteínas e cinzas no texturizado de soja foi próximo ao encontrado em farinha de soja texturizada por CASTELLANOS MOLINA [6], que apresentou $51,0 \%$ de proteínas e $6,0 \%$ de cinzas.

TABELA 2 - Composição centesimal aproximada (\% base úmida) das matérias-primas e da formulação final da barra de cereais funcional sabor banana ${ }^{1}$

\begin{tabular}{lcccc}
\hline Componente & $\begin{array}{c}\text { Proteína } \\
\text { texturizada } \\
\text { de soja }\end{array}$ & Aveia & $\begin{array}{c}\text { Gérmen de } \\
\text { trigo }\end{array}$ & $\begin{array}{c}\text { Barra de } \\
\text { cereais }\end{array}$ \\
\hline Proteínas $(\mathrm{N} \times 6,25)$ & $53,41 \pm 0,127$ & $14,50 \pm 0,097$ & $35,32 \pm 0,178^{*}$ & $15,31 \pm 0,035$ \\
Matéria graxa & $0,36 \pm 0,005$ & $7,84 \pm 0,069$ & $10,57 \pm 0,029$ & $5,64 \pm 0,05$ \\
Fibras totais & $15,30 \pm 0,001$ & $10,38 \pm 0,001$ & $12,77 \pm 0,003$ & $5,17 \pm 0,004$ \\
Fibras insolúveis & $11,35 \pm 0,003$ & $7,78 \pm 0,001$ & $10,41 \pm 0,004$ & $4,30 \pm 0,004$ \\
Fibras solúveis & $3,94 \pm 0,003$ & $2,60 \pm 0,002$ & $2,37 \pm 0,006$ & $0,87 \pm 0,0007$ \\
Cinzas & $6,45 \pm 0,039$ & $1,80 \pm 0,001$ & $4,58 \pm 0,186$ & $2,20 \pm 0,009$ \\
Umidade & $2,92 \pm 0,054$ & $9,42 \pm 0,091$ & $10,99 \pm 0,192$ & $10,71 \pm 0,25$ \\
Carboidratos ${ }^{* *}$ & 21,56 & 56,06 & 22,36 & 60,97 \\
\hline${ }^{1}$ Médias de três replicatas & \multicolumn{4}{c}{} \\
${ }^{*}$ Proteína, \% (Nx5,7) & \\
${ }^{* * *}$ Teor de carboidratos calculado por diferença & & \\
\end{tabular}

A formulação final da barra de cereais funcional apresentou, em média, 15,31\% de proteína, teor superior e desejável em relação aos produtos encontrados no mercado (com valores médios de 4,4\% de proteína). Apresentou também menor teor de carboidratos e maior conteúdo de fibras totais, que são, em média, 74,0 e 4,0\%, respectivamente. O conteúdo de matéria graxa apresentou-se satisfatório $(5,64 \%)$ em relação aos produtos convencionais, que apresentam teores de 4,0 a $12,0 \%$.

ESTÉVEZ et al. [12] manufaturaram barra de cereais contendo gérmen de trigo, aveia e nozes que apresentaram teores de proteínas e cinzas semelhantes ( 16,5 e $2,2 \%$ respectivamente), porém de menor conteúdo de fibras (3,3\%). A descrição dos minerais presentes na formulação final da barra de cereais está apresentada na Tabela 3.

TABELA 3 - Conteúdo (base úmida) de nitrogênio, macro e micro minerais da barra de cereais funcional sabor banana ${ }^{1}$

\begin{tabular}{lcccccc}
\hline & $\mathbf{N}$ & $\mathbf{P}$ & $\mathbf{K}$ & $\mathbf{C a}$ & $\mathbf{M g}$ & $\mathbf{S}$ \\
\hline $\mathrm{g} / 100 \mathrm{~g}$ & 2,520 & 0,384 & 0,497 & 0,082 & 0,077 & 0,090 \\
$(\%) \mathrm{IDR}^{*}$ & - & 48,00 & - & 10,25 & 25,66 & - \\
\hline & $\mathbf{B}$ & $\mathbf{C u}$ & $\mathbf{F e}$ & $\mathbf{M n}$ & $\mathbf{M o}$ & $\mathbf{Z n}$ \\
\hline $\mathrm{mg} / 100 \mathrm{~g}$ & 0,540 & 0,365 & 5,105 & 3,515 & - & 2,955 \\
$(\%) \mathrm{IDR}^{*}$ & - & 12,16 & 36,46 & 70,3 & - & 19,70 \\
\hline
\end{tabular}

${ }^{1}$ Médias de duas replicatas

*(\%) da Ingestão Diária Recomendada (IDR) para pessoas adultas baseada em uma dieta de $2.500 \mathrm{Kcal}$, segundo Committee on Dietary Allowances, Food and Nutrition Board [9]
A formulação funcional de barra de cereais apresentou elevado conteúdo de minerais importantes como fósforo (P) e cálcio (Ca), com teores compatíveis aos encontrados em alimentos ricos em fósforo, como feijão $(0,471 \mathrm{~g} / 100$ g) e gema de ovo $(0,5 \mathrm{~g} / 100 \mathrm{~g})$, e em cálcio, como o leite integral $(91 \mathrm{mg} / 250 \mathrm{~mL})$. Destacaram-se também presentes os micro minerais essenciais cobre $(\mathrm{Cu})$, ferro $(\mathrm{Fe})$, manganês $(\mathrm{Mn})$ e zinco $(\mathrm{Zn})$, com teores consideráveis de manganês (70,3\% IDR) e teor de ferro semelhante aos encontrados em alimentos como castanha $(5,5 \mathrm{mg} / 100 \mathrm{~g})$ e trigo $(5,0 \mathrm{mg} / 100 \mathrm{~g})$.

Oligossacarídeos e isoflavonas determinados na proteína texturizada de soja utilizada na formulação das barras de cereais estão descritos na Tabela 4. Verificou-se que os teores dos açúcares sacarose, rafinose e estaquiose encontrados na proteína texturizada de soja se mostraram superiores aos teores relacionados ao grão, farinha integral e, principalmente, ao isolado protéico de soja, encontrados por RODRIGUES [28], que foram de $0,28 \mathrm{~g} / 100 \mathrm{~g}$ de rafinose no grão de soja e $0,3 \mathrm{~g} / 100 \mathrm{~g} \mathrm{em}$ farinha integral; $1,68 \mathrm{mg} / 100 \mathrm{~g}$ de estaquiose no grão, $1,86 \mathrm{mg} / 100 \mathrm{~g}$ na farinha integral e $0,024 \mathrm{mg} / 100 \mathrm{~g}$ no isolado protéico de soja.

Os teores das isoflavonas daidzina, genistina, daidzeína e genisteína também se mostraram superiores aos determinados no grão, farinha integral e isolado protéico, relatados pelo mesmo autor (respectivamente: $17,03 \mathrm{mg} / 100 \mathrm{~g}$, $21,77 \mathrm{mg} / 100 \mathrm{~g}, 1,02 \mathrm{mg} / 100$ g e $1,36 \mathrm{mg} / 100$ g de matéria seca em grão de soja; $46,12 \mathrm{mg} / 100 \mathrm{~g}, 60,44 \mathrm{mg} / 100 \mathrm{~g}$, $5,42 \mathrm{mg} / 100 \mathrm{~g}$ e $3,36 \mathrm{mg} / 100 \mathrm{~g}$ de matéria seca em farinha integral; e 23,24 mg/100 g, 49,16 mg/100 g, 7,62 mg/100 g e $8,62 \mathrm{mg} / 100 \mathrm{~g}$ de matéria seca em isolado protéico). ARAÚJO, CARLOS \& SEDYAMA [2] encontraram maiores teores de daidzina e genistina $(159,3 \mathrm{mg} / 100 \mathrm{~g}$ e 239,0 $\mathrm{mg} / 100 \mathrm{~g})$ e menores de genisteína e daidzeína $(8,7 \mathrm{mg} / 100 \mathrm{~g}$ e $2,2 \mathrm{mg} / 100 \mathrm{~g}$ ) em matéria liofilizada de grão de soja.

TABELA 4 - Conteúdo de oligossacarídeos e isoflavonas em proteína texturizada de soja ${ }^{1}$

\begin{tabular}{lc}
\hline Oligossacarídeos & $\mathbf{g} / \mathbf{1 0 0} \mathbf{g}$ (base úmida) \\
\hline Sacarose & 9,48 \\
Rafinose & 1,92 \\
Estaquiose & 4,66 \\
\hline Isoflavonas & $\mathbf{m g} / \mathbf{1 0 0} \mathbf{~ g ~ ( b a s e ~ s e c a ) ~}$ \\
\hline Daidzina & 59,97 \\
Genistina & 87,68 \\
Mal-daidzina & 46,01 \\
Mal-genistina & 69,56 \\
Daidzeína & 9,85 \\
Genisteína & 10,41 \\
\hline TOTAL & $\mathbf{2 8 3 , 4 9}$
\end{tabular}

${ }^{1}$ Médias de duas replicatas

Os teores de tocoferóis totais nos ingredientes e na barra de cereais funcional estão descritos na Tabela 5. Verificou-se uma redução no conteúdo de tocoferóis totais no gérmen de trigo após o processo de torração, porém sem comprometimento severo. Os teores de vitamina $\mathrm{E}$ 
no gérmen de trigo estão em concordância com relatos de MARQUES [21], que foi de 23,45 mg/100 g em matéria seca. Houve boa preservação da vitamina E (acetato de $\alpha$ tocoferol $50 \%$ ) após o processamento das barras de cereais, adicionada na formulação em $300 \mathrm{mg} / 100 \mathrm{~g}$.

TABELA 5 - Tocoferóis totais (vitamina E) em gérmen de trigo, gérmen de trigo torrado, lecitina de soja e barra de cereais funcional sabor banana ${ }^{1}$

\begin{tabular}{lc}
\hline & $\mathrm{mg} / 100 \mathrm{~g}$ (base úmida) \\
\hline Gérmen de trigo & 29,95 \\
Gérmen de trigo torrado* & 24,05 \\
Lecitina de soja & 82,74 \\
Barra de cereais funcional & 118,0 \\
${ }^{1}$ Médias de duas replicatas & \\
${ }^{*}$ O gérmen de trigo teve seu teor de umidade ajustado para $28 \%$ e a torração foi realizada \\
em estufa a $180^{\circ} \mathrm{C}$ por 8 min
\end{tabular}

\section{2 - Avaliação Sensorial}

As notas atribuídas pelos consumidores às formulações de barra de cereais quanto à preferência sensorial estão apresentadas na Tabela 6 . Os resultados do teste de ideal de doçura e acidez estão representados pela Figura 1.

TABELA 6 - Médias das notas atribuídas pelos consumidores para a preferência sensorial das formulações de barra de cereais funcional sabor banana ${ }^{1}$

\begin{tabular}{lccccc}
\hline Formulação & Aparência & Cor & Sabor & Textura & $\begin{array}{c}\text { Impressão } \\
\text { Global }\end{array}$ \\
\hline C & $6,05 \mathrm{a}$ & $6,62 \mathrm{a}$ & $5,32 \mathrm{~b}$ & $4,08 \mathrm{ab}$ & $5,70 \mathrm{a}$ \\
B & $6,39 \mathrm{a}$ & $6,58 \mathrm{a}$ & $6,42 \mathrm{a}$ & $5,29 \mathrm{a}$ & $6,14 \mathrm{a}$ \\
A & $4,03 \mathrm{~b}$ & $5,26 \mathrm{~b}$ & $5,11 \mathrm{~b}$ & $4,34 \mathrm{~b}$ & $4,66 \mathrm{~b}$ \\
\hline $\begin{array}{l}\text { 1Médias com letras iguais, na mesma coluna, não diferem entre si estatisticamente } \\
(\mathrm{p}>0,05)\end{array}$
\end{tabular}

As formulações de barra de cereais com ingredientes funcionais e diferentes teores de ácido ascórbico (vitamina C) apresentaram, de um modo geral, boa preferência sensorial de sabor e aspectos visuais de cor e aparência. No entanto, a sensação de textura originada da combinação dos ingredientes utilizados obteve menores médias de preferência sensorial.

Com relação ao atributo sabor, a formulação B, de teor de ácido ascórbico intermediário, obteve maior preferência apresentando nota média de 6,42; diferindo significativamente $(p \leq 0,05)$ das demais formulações. As formulações A e C não diferiram estatisticamente entre si, resultados que indicam que a maior e menor acidez conseqüente das adições de ácido ascórbico interferiram igualmente na diminuição da preferência do sabor das barras de cereais.

Quanto à aparência, textura e impressão global, a formulação B apresentou maiores médias, não diferindo, porém, significativamente $(\mathrm{p}>0,05)$ da formulação $\mathrm{C}$, de menor teor de ácido ascórbico. O maior teor de ácido ascórbico na formulação de barra de cereais (A) apresentou notas médias significativamente $(\mathrm{p} \leq 0,05)$ menores de preferência que as demais formulações para os atributos aparência, cor e impressão global. Estes resultados indicaram que quantidades elevadas de ácido ascórbico levaram a uma rejeição dos consumidores, principalmente nas características visuais.

A aparência, a cor e a impressão global foram prejudicadas nesta formulação provavelmente devido ao escurecimento mais acelerado das barras de cereais provocado pela oxidação da vitamina C. As barras de cereais foram retiradas das embalagens imediatamente antes da avaliação, porém o oxigênio residual no interior das embalagens seria suficiente para catalisar a reação.

Segundo FENNEMA [ 14], o ácido ascórbico é altamente sensível a várias formas de degradação, e os fatores que podem influenciar a natureza e velocidade do mecanismo de degradação incluem a concentração inicial de ácido ascórbico entre outros, como temperatura, concentração de sal e açúcar, pH, oxigênio, enzimas, catalisadores metálicos e razão entre ácido ascórbico e dehidroascórbico.

No teste de escala do ideal (Figura 1), 57,7\% dos consumidores assinalaram "doçura ideal" e 53,3\% "acidez ideal" para a formulação B adicionada de $1,1 \mathrm{~g} / 100 \mathrm{~g}$ de ácido ascórbico; enquanto 86,94\% dos consumidores assinalaram entre "ligeiramente" e "extremamente mais ácido que o ideal” para a formulação adicionada de 2,0 g/100 g de ácido ascórbico (A), o que pode estar associado à menor média de preferência para o atributo sabor desta formulação.

Observou-se, também (Figura 1), o efeito da concentração de ácido ascórbico e suas respectivas sensações de acidez sobre a doçura das formulações de barras de cereais. O equilíbrio entre a doçura e a acidez foi encontrado na formulação B, adicionada de concentração intermediária de ácido ascórbico ( 1,1 g/100 g). Para a formulação adicionada de menor teor de ácido ascórbico (C), os consumidores perceberam maior sensação de doçura, deslocando a escala de ideal de doçura para a direita, entre os níveis 0 (ideal) e +4 (extremamente mais doce que o ideal).

O oposto aconteceu na formulação de maior teor de ácido ascórbico (A), onde a doçura percebida se concentrou entre os níveis -3 (muito menos doce que o ideal) e 0 (ideal) da escala. Uma vez que a concentração de açúcares das formulações das barras de cereais não variou, estes resultados indicam que a acidez correspondente à variação do teor de ácido ascórbico adicionado teve influência sobre a percepção de doçura dos provadores, apresentando uma relação inversa de quanto maior a acidez, menor a sensação de doçura percebida.

\section{4 - CONCLUSÃO}

A formulação da barra de cereais funcional à base de proteína de soja texturizada, gérmen de trigo, aveia e vitaminas apresentou, em média, 15,3\% de proteína, teor desejável em relação aos produtos encontrados no mercado (que apresentam, em média, 4,4\% de proteína), maior conteúdo de fibras totais $(5,17 \%)$ e satisfatório conteúdo de matéria graxa $(5,64 \%)$ em relação aos produtos convencionais. A 


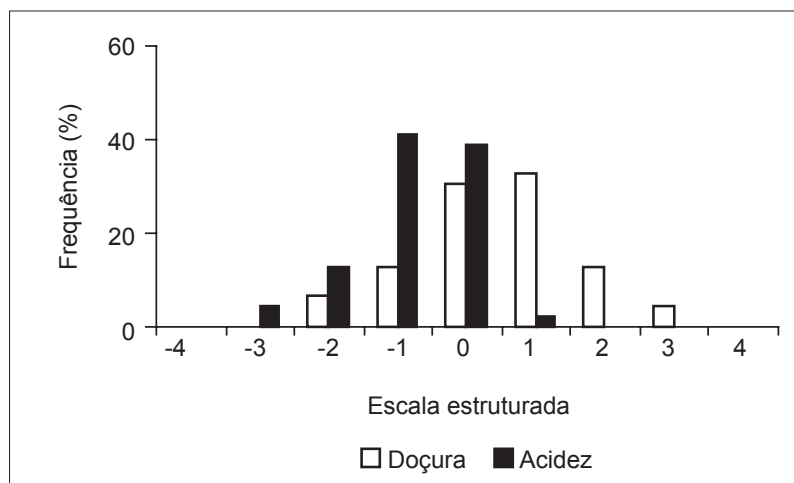

(C)

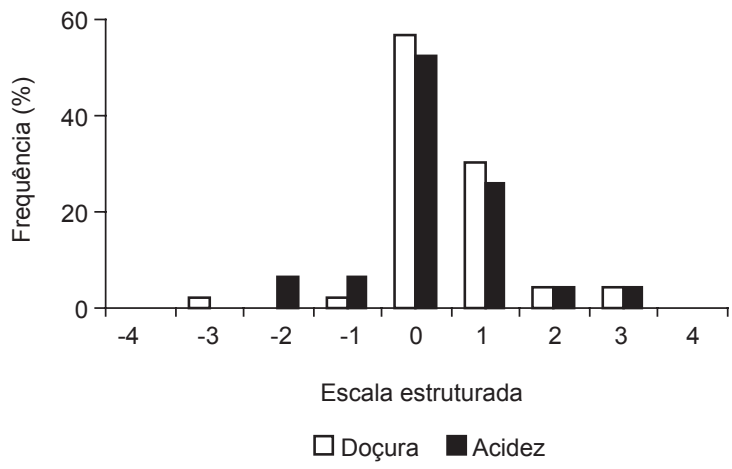

(B)

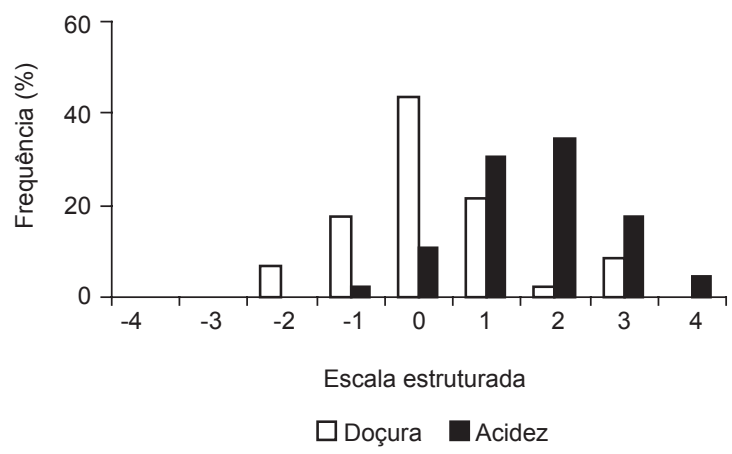

(A)

-4: Extremamente menos doce/ácido que o ideal

+4: Extremamente mais doce/ácido que o ideal

Figura 1 - Freqüência dos valores atribuídos na escala de ideal de doçura e acidez para as formulações de barra de cereais adicionadas de 2,0 g/100 g (A); 1,1 g/100 g (B) e 0,2 g/100 g (C) de ácido ascórbico

formulação funcional apresentou também elevado teor de vitamina $\mathrm{E}$ e de minerais e micro minerais essenciais como fósforo $(\mathrm{P})$, cálcio $(\mathrm{Ca})$, cobre $(\mathrm{Cu})$, ferro $(\mathrm{Fe})$, manganês $(\mathrm{Mn})$ e zinco $(\mathrm{Zn})$, com teores compatíveis aos encontrados em alimentos ricos nestes nutrientes.

As diferentes concentrações de ácido ascórbico na formulação da barra de cereais resultaram em diferenças significativas $(\mathrm{p} \leq 0,05)$ na preferência sensorial de todos os atributos avaliados. Porém, o maior teor adicionado (2\%) apresentou menor preferência principalmente nas características visuais, devido ao escurecimento resultante da oxidação da vitamina, e no atributo sabor, confirmado pelo teste de escala do ideal, pois cerca de 56\% dos consumidores assinalaram entre "moderadamente" ou "muito" ou "extremamente mais ácido que o ideal". A acidez apresentou uma relação inversa à doçura nas barras de cereais, sendo que quanto maior a acidez, menor foi a sensação de doçura percebida pelos consumidores.

\section{5 - REFERÊNCIAS BIBLIOGRÁFICAS}

[1] AOAC - Association of Official Analytical Chemistry. Official methods of analysis of the Association of Official Analutical Chemistry. $16^{\text {th }}$ ed., Washington, 1997.

[2] ARAÚJO, J.M.A.; CARLOS, J.C.S.; SEDYAMA, C.S. Isoflavonas em grãos de soja; importância da atividade de $\beta$-glicosidase na formação do sabor amargo e adstringente. Ciência e Tecnologia de Alimentos, v. 17, n. 2, p. 137-141, mai.-ago., 1997.

[3] BARBOSA, M. Na onda da barra. Com uma gestão alternativa e um produto campeão de vendas, $\mathrm{Nu}$ trimental afasta a crise e volta a ser uma empresa saudável. Disponível em: http://www.terra.com. br/istoedinheiro. Acesso em: 16 set. 2003.

[4] BOUSTANI, P.; MITCHELL, V.-W. Cereal bars: a perceptual, chemical and sensory analysis. British Food Journal, v. 92, n. 5, p. 17-22, 1990.

[5] BOWER, J.A.; WHITTEN, R. Sensory characteristics and consumer linking for cereal bar snack foods. Journal of Sensory Studies, v. 15, n. 3, p. 327 345, 2000.

[6] CASTELLANOS MOLINA, R. Contribuição ao estudo de substituição parcial de carne por proteína texturizada de soja na elaboração de "hambúrguer". Campinas, 1977. Tese (mestrado em Tecnologia de Alimentos) - Faculdade de Engenharia de Alimentos e Agrícola, Universidade Estadual de Campinas (Unicamp).

[7] CHANG, H.C.; CHURCHWELL, M.I.; DELCLOS, K.B.; NEWBOLD, N.N.; DOERGE, D.R. Mass spectrometric determination of genistein tissue distribuition in dietexposed sprague-dawley rats. Journal of Nutrition, v. 130, p. 1.963-1.970, 2000.

[8] CLARKSON, P.M. Antioxidants and physical performance, Critical Reviews in Food Science and Nutrition, v. 35, n. 1/2, p. 131-141, Jan., 1995.

[9] COMMITTEE ON DIETARY ALLOWANCES, FOOD AND NUTRITION BOARD. Recommended Dietary Allowances (RDA), $10^{\text {th }}$ revised edition, National Academy of Science (NAS), Washington D.C., 1989.

[10] CONTRERAS GUZMÁN, E.S.; STRONG III, F.C. Determination of tocopherols (vitamin E) by reduction of cupric ion. Journal of Association Analytical Chemistry, n. 65, v. 5, p. 1.215-1.221, 1982.

[ 11 ] DJAHANSOUZI, S.; BRAESEN, J.H.; KOENING, K.; BEISIEGEL, U.; KONTUSH, A. The effect of pharmacological doses of different oxidants on oxidation parameters and atherogenesis in hyperlipidaemic rabbits. Atherosclerosis, v. 154, n. 2, p. 387-398, Feb., 2001. 
[12] ESTÉVEZ, A.M.; ESCOBAR, B.; VÁZQUEZ, M.; CASTILLO, E.; ARAYA, E.; ZACARÍAS, I. Cereal and nut bars, nutritional quality and storage stability. Plant Foods for Human Nutrition, v. 47, n. 4, p. 309-317, 1995.

[13] FRANCAL FEIRAS. Barra de cereais: grande filão para comércio com EUA. Disponível em: http:// www.francal.com.br/codigo/p-noticias-conteudo. asp?noticias $I D=758$. Acesso em: 16 set. 2003 .

[14] FENNEMA, O.R. Química de los Alimentos. Zaragoza: Editorial Acribia S.A., 1993.

[15] HART, F. Caracterização química da cultivar UPF 18 e estudo das farinhas estabilizadas termicamente por vapor e água quente. Pelotas, 2001, 109 p. Tese (mestrado em Ciência e Tecnologia Agroindustrial) - Faculdade de Agronomia Eliseu Maciel. Universidade Federal de Pelotas.

[16] HOLDER, C.L.; CHURCHWELL, M.I.; DOERGE, D.R. Quantification of soy isoflavones, genistein and daidzein, and conjugates in rat blood using LC/ES-MS. Journal of Agricultural and Food Chemistry, v. 47, p. 3.764-3.770, 1999

[17] ISMAIL, N.M.; GHAFAR, N.A.; JAARIN, K.; KHINE, J.H.; TOP, G.M. Vitamin E and factors affecting atherosclerosis in rabbits fed a cholestrol-rich diet. International Journal of Food Sciences and Nutrition, v. 51, suppl. 1, p. 79-94, Dec., 2000.

[18] KHOR, H.T.; NG, T.T. Effects of administration of alpha-tocopherol and tocotrienols on serum lipids and liver HMG CoA reductase activity. International Journal of Food Sciences and Nutrition, v. 51, suppl. 1, p. 3-11, Dec, 2000.

[19] LEENHEER, A.P.; LAMBERT, W.E.; RUYTER, M.G.M. Modern chromatographic analysis of the vitamins. New York: Marcel Decker, 1985

[20] MAHUNGU, S.M.; DIAZ-MERCADO, S.; LI, J.; SCHWENK, M.; SINGLETARY, K.; FALLER, J. Stability of isoflavones during extrusion processing of corn/soy mixture. Journal of Agricultural and Food Chemistry, v. 47, p. 279-284, 1999.

[21] MARQUES, L.M.R. Efeito da temperatura de extrusão, umidade da matéria-prima, teor de amido e sacarose nas características tecnológicas e nutricionais de produtos extrusados de germe de trigo. Campinas, 1992. Tese (Mestre em Tecnologia de Alimentos) - Faculdade de Engenharia de Alimentos, Universidade Estadual de Campinas (Unicamp).

[22] NORMAS ANALÍTICAS DO INSTITUTO ADOLFO LUTZ. Métodos químicos e físicos para análise de alimentos. $2^{\mathrm{a}}$ ed., v. 1, São Paulo, 1976.

[23] PALAZZOLO, G. Cereal bars: they're not just for breakfast anymore. Cereal Foods World, v. 48, n. 2, Mar.-Apr., p. 70-72, 2003.

[24] PEHANICH, M. No holds barred. Prepared foods, v. 172, n. 3, Mar., p. 79-80, 2003.

[25] POMERANZ, Y. Wheat chemistry and technology. St. Paul, Minnesota: American Chemistry Incorporation, 1971.
[26] POMERANZ, Y. Wheat chemistry and technology. $3^{\text {rd }}$ ed. St. Paul, Minnesota: American Chemistry Incorporation, 1988.

[27] RINSE, J. Arteriosclerose, química e nutrição: algumas observações, experiências e uma hipótese. Tradução Roberto H. Moretti. American Laboratory: 37., p. 19., s.d.

[28] RODRIGUES, R.S. Caracterização de extratos de soja obtidos de grãos, farinha integral e isolado protéico visando a formulação e avaliação biológica (em coelhos) de bebida funcional à base de extrato de soja e polpa de pêssegos. Campinas, 2003. Tese (doutorado em Tecnologia de Alimentos) - Faculdade de Engenharia de Alimentos, Universidade Estadual de Campinas (Unicamp).

[29] SALONEN J.T.; NYYSÖNEN, K.; SALONEN, R.; LAKKA, H.-M.; KAIKKONEN, J.; PORKKALA-SARATAHO, E.; VOUTILAINEN, S.; LAKKA, T.A.; RISSANEN, T.; LESKINEN, L.; TUOMAINEN, T.-P.; VALKONEN, V.-P.; RISTONMAA, U.; POULSEN, H.E. Antioxidant supplementation in atherosclerosis prevention (ASAP) study: a randomized trial of the effect of vitamins $\mathrm{E}$ and $\mathrm{C}$ on 3-year progression of carotid atherosclerosis. Journal of Internal Medicine, v. 248, p. 377-386, 2000.

[30] SARRUGE, J.R.; HAAG, H.P. Análises químicas em plantas. Piracicaba: Esalq, 1974.

[31] SAS Institute. SAS user's guide: statistics. Cary, USA: SAS Inst., 1993.

[32] SIDHU, J.S.; AL-HOOT, S.N.; AL-SAQER, J.M. Effect of adding wheat brain and germ fractions on the chemical composition of high-fiber toast bread. Food Chemistry, v. 67, p. 365-371, 1999.

[33] SIGMA. Total dietary fiber assay kit. Technical Bulletin $\mathrm{N}^{\mathrm{O}}$ TDFAB-3, Jun. 2000.

[34] STAVRIC, B. Antimutagens and anticarcinogens in foods. Food and Chemical Toxicology, v. 32, n. 1, p. 79-90, Jan. 1994.

[35] STONE, H.; SIDEL, J.L. Sensory evaluation practices. $2^{\text {nd }}$ ed. London: Academic Press, 1993.

[36] VEINBERGS, I.; MALLORY, M.; SAGARA, Y.; MASLIHA, E. Vitamin E supplementation prevents spatial learning deficits and dendritic alterations in aged apolipoprotein $\mathrm{E}$ - deficient mice. European Journal of Neurosciense, v. 12 , n. 12, p. 4.541-4.546, Dec. 2000.

[37] VIDAL-VALVERDE, C.; FRÍAS, J.; VALVERDE, S. Changes in carbohidrate composition of legumes after soaking and cooking. Journal of the American Dietetic Association, n. 5, v. 93, May, p. 547-550, 1993.

[38] WASZCZYNSKY, N.J. Extração de proteínas do farelo de trigo com aplicação de enzimas. Londrina, 1979. Tese (mestrado em Ciência de Alimentos) - Faculdade de Engenharia de Alimentos, Universidade Estadual de Londrina.

[39] YAMAKOSHI, J.; PISKULA M.K.; IZUMI, T.; TOBE, K.; SAITO, M.; KATAOKA, S.; OBATA, A.; KIKUCHI, M. Isoflavone aglicone-rich extract without soy protein attenuates atherosclerosis development in cholesterol-fed rabbits. Journal of Nutriton, v. 130, p. 1.887-1.893, 2000. 